\title{
A STUDY OF PERIOPERATIVE SURGICAL COMPLICATIONS IN EYES WITH PSEUDOEXFOLIATION UNDERGOING CATARACT SURGERY
}

\author{
Vijay Kumar Srivastava1, Ramya Ravishankar Nadig², Kunal Verma ${ }^{3}$
}

1 Professor and HOD, Department of Ophthalmology, MVJ Medical College and Research Hospital, Hoskote, Bangalore, Karnataka, India. ${ }^{2}$ Resident, Department of Ophthalmology, MVJ Medical College and Research Hospital, Hoskote, Bangalore, Karnataka, India. ${ }^{3}$ Resident, Department of Ophthalmology, MVJ Medical College and Research Hospital, Hoskote, Bangalore, Karnataka, India.

\section{ABSTRACT}

\section{BACKGROUND}

Pseudoexfoliation Syndrome (PES) is an age-related systemic microfibrillopathy, caused by progressive accumulation and gradual deposition of extracellular grey and white material over various tissues including eyes. Pseudoexfoliation (PXE) is a systemic condition which affects eyes in advanced ages in which period, cataract is also common. PXE poses various problems during cataract surgery like poor pupillary dilatation and zonular instability. We wanted to analyse perioperative complications in cataract surgery in presence of PXE.

\section{MATERIALS AND METHODS}

It was a prospective observational study conducted in a tertiary hospital from December 2016 to May 2018. 124 patients having cataract and PEX and who were above 50 years of age were included in the study. Cataract surgery was performed, and perioperative complications documented and statistically analysed.

\section{RESULTS}

Poor pupillary dilatation which occurred in $47.58 \%$ was the most common cause of surgical difficulty. Pupillotomy and other pupillary dilation devices were used. Other complications noted were subluxation of lens, rupture of posterior capsule, vitreous loss, retained lens matter, and dehiscence of zonules.

\section{CONCLUSIONS}

When cataract presents with PXE, there is an increased risk of surgical complications, the main being rigid pupil. Recognition of PXE preoperatively with proper examination and its management during surgery with various techniques and devices is essential to give a good vision to the patient.

\section{KEY WORDS}

Pseudoexfoliation, Zonular Weakness, Pupillotomy, Cataract

HOW TO CITE THIS ARTICLE: Srivastava VK, Nadig RR, Verma K. A study of perioperative surgical complications in eyes with pseudoexfoliation undergoing cataract surgery. J. Evolution Med. Dent. Sci. 2019;8(11):815-818, DOI: 10.14260/jemds/2019/180

\section{BACKGROUND}

Pseudoexfoliation syndrome (PES) is an age-related systemic microfibrillopathy, caused by progressive accumulation and gradual deposition of extracellular grey and white material over various tissues including eyes.

Lindberg, who first described Pseudoexfoliation (PXE) in 1917 believed this material to be a product of earlier inflammation.[1] Swiss Ophthalmologist Alfred Vogt while describing it fully in 1918, thought it to be a remnant of papillary membrane.[2] Now it is believed that the ageing epithelial cells in equatorial lens capsule, trabeculum, iris at pupillary margin, ciliary body produce extracellular pseudoexfoliative material which is grey white and fibrogranular in nature. [3] Its presence in skin and visceral organs suggest that it is a systemic disorder. ${ }^{[4]}$

'Financial or Other Competing Interest': None.

Submission 24-01-2019, Peer Review 27-02-2019,

Acceptance 06-03-2019, Published 18-03-2019.

Corresponding Author:

Dr. Vijay Kumar Srivastava,

Villa 41, Krishna Kuteer Green House,

Near Shobha Amethyst,

Kannamangala Road,

Bangalore-560067,

Karnataka, India.

E-mail: vks_4186@rediffmail.com

DOI: $10.14260 /$ jemds $/ 2019 / 180$

\section{(c) $(i) \ominus$}

A South Indian study reported prevalence of PXE as 3.8\%, while the Andhra Pradesh Eye Disease Study reported it as $3.01 \%,[5,6]$ PXE usually seen in the elderly age group and it is this same group of patients who will possibly undergo cataract surgery.

Pseudoexfoliative material (PXM) is seen deposited in three zones: in central pupillary area, peripheral preequatorial area and a central clear zone where the material has been brushed off by pupillary movements. The PXM can be observed like dandruff at pupillary margin. Iris sphincter gives moth eaten appearance on transillumination. Deposits can be observed on endothelial surface of cornea, gonioscopy shows PXM on trabecular meshwork with pigmentation, sometimes with a pigmented Sampaolesi line anterior to Schwalbes line.

PXM is fibrillar extracellular material consisting of a protein core surrounded by glycosaminoglycans produced by ageing epithelial cells of basement membranes of the iris, ciliary body and lens epithelium. It can also be produced by the basement membranes of endothelial cells of iris and conjunctival vessels and with trabecular endothelial cells.

Recent genetic studies in multiple populations have identified the lysyl oxidase-like 1 (LOXL1) gene as one of the major contributors to the risk of developing pseudoexfoliation syndrome and pseudoexfoliation glaucoma.[7] 
Prevalence of PEX has been correlated with cardiovascular diseases such as transient ischaemic attacks, stroke, hypertension, angina, myocardial infarction and negatively with diabetes mellitus.[8,9]

Presence of PEX makes cataract surgery challenging due to poor dilatation of pupil and zonular instability. Scorolli et al.[10] found that the chances of intraoperative complications during cataract surgery are five times higher than that in normal population. In view of this it becomes imperative to detect presence of PEX preoperatively by dilating pupil and thorough examination.

This study was done with the aim of studying the pattern of intra-operative and post-operative complications during the cataract surgery in patients with PXE.

\section{MATERIALS AND METHODS}

It was a prospective observational study conducted in a tertiary hospital from December 2016 to May 2018 after obtaining ethical clearance of institutional ethical committee. 124 patients having cataract and PEX and who were above 50 years of age were included in the study. Those having complicated cataract, trauma and with previous surgery were excluded.

All patients were admitted on the previous day of surgery. Detailed examination of eye was done including visual acuity assessment, slit lamp examination gonioscopy, funduscopy and IOP measurement.

The presence of PEX material was confirmed by looking for white, fluffy, fibrillar or granular material at the pupillary margin or on the anterior lens surface after pupillary dilatation. Cataract type was classified as nuclear, cortical, posterior sub capsular (PSC), mature and mixed type based on slit lamp examination.

Pupillary diameter was measured after dilatation. A scan biometry, Keratometry and IOL power calculation was done. All the cases were operated by experienced surgeons either by Small Incision Cataract surgery (SICS) or by Phacoemulsification.

Pre-operatively Moxifloxacin eye drops were instilled from previous evening. Flurbiprofen drops were instilled three times in morning of surgery at half hourly interval. Pupil was dilated with tropicamide plus Phenylephrine drops and also 2\% Homatropine drops.

Peribulbar anaesthesia with lignocaine, Bupivacaine and Hyaluronidase was given in all cases. Standard SICS was done and posterior chamber IOL with $6 \mathrm{~mm}$ optic implanted. In cases undergoing phacoemulsification clear corneal incision was used and foldable IOL implanted.

Post operatively patients were put on steroids and antibiotic drops which were tapered gradually over 6 weeks. Post-operative follow-up was done on post-operative day 1 , day 7 , day 14, then every two weeks for 3 months. Postoperative finding regarding inflammation, IOP, position of IOL and other findings were carefully noted and tabulated. Statistical analysis was done using statistical package for social sciences version 15.0 (IBM).

\section{RESULTS}

$17.74 \%$ patients were in the age group of $50-60,43.55 \%$ patients were in the age group of $60-70$ and $38.71 \%$ patients were in the age group of $70-80.52 .42 \%$ patients were male, and $47.58 \%$ patients were female. Majority of patients were in the age group of 60-70. Male patients were more in number than female patients in our study. [Table-1]

$7.26 \%$ of patients had preoperative visual acuity of $6 / 6$ $6 / 24,13.71 \%$ had $6 / 36-6 / 60,47.58 \%$ had counting fingers (CF), $19.36 \%$ had HM, and $12.09 \%$ had PL/PR. Majority of the patients had preoperative vision of CF. [Table-2]

Poor pupillary dilatation was found in $47.58 \%$ patients, Subluxation or dislocation of lens in $1.61 \%$, Rupture of post capsule in $4.84 \%$, Vitreous loss in $5.64 \%$, Lens matter retained in $6.45 \%$, IOL decentration in $4.03 \%$, Dehiscence of Zonules $3.22 \%$, and Post-operative Hyphema in $0.80 \%$. [Table-3]

Post-operative Vision was mostly good. 6/6 - 6/12 vision was found in $54.84 \%$ patients, $6 / 18-6 / 36$ in $37.90 \%$ and $6 / 60$ or less in $7.26 \%$ patients. [Table-4]

\begin{tabular}{|c|c|c|c|c|}
\hline Age & Male & Female & Total & Percentage \\
\hline $50-60$ & 10 & 12 & 22 & 17.74 \\
\hline $60-70$ & 29 & 25 & 54 & 43.55 \\
\hline $70-80$ & 26 & 22 & 48 & 38.71 \\
\hline Total & $\mathbf{6 5}$ & $\mathbf{5 9}$ & $\mathbf{1 2 4}$ & $\mathbf{1 0 0}$ \\
\hline \multicolumn{5}{|c|}{ Table 1. Age-Sex Distribution } \\
\hline
\end{tabular}

\begin{tabular}{|c|c|c|}
\hline Vision & Number & Percentage \\
\hline $6 / 6-6 / 24$ & 9 & 7.26 \\
\hline $6 / 36-6 / 60$ & 17 & 13.71 \\
\hline CF & 59 & 47.58 \\
\hline HM & 24 & 19.36 \\
\hline PL/PR & 15 & 12.09 \\
\hline Total & $\mathbf{1 2 4}$ & $\mathbf{1 0 0}$ \\
\hline \multicolumn{3}{|c|}{ Table 2. Pre-Op Vision } \\
\hline
\end{tabular}

\begin{tabular}{|c|c|c|c|}
\hline $\begin{array}{c}\text { Sl. } \\
\text { No. }\end{array}$ & Complications & No. & $\mathbf{\%}$ \\
\hline 1. & Poor Papillary Dilatation & 59 & 47.58 \\
\hline 2. & Subluxation or Dislocation of Lens & 2 & 1.61 \\
\hline 3. & Rupture of Post Capsule & 6 & 4.84 \\
\hline 4. & Vitreous Loss & 7 & 5.64 \\
\hline 5. & Lens Matter Retained & 8 & 6.45 \\
\hline 6. & IOL Decentration & 5 & 4.03 \\
\hline 7. & Dehiscence of Zonules & 4 & 3.22 \\
\hline 8. & Post-Operative Hyphema & 1 & 0.80 \\
\hline \multicolumn{3}{|c|}{ Table 3. Complications } \\
\hline
\end{tabular}

\begin{tabular}{|c|c|c|}
\hline Vision & Number & Percentage \\
\hline $6 / 6-6 / 12$ & 68 & 54.84 \\
\hline $6 / 18-6 / 36$ & 47 & 37.90 \\
\hline $6 / 60$ or less & 9 & 7.26 \\
\hline \multicolumn{2}{|c|}{ Table 4. Post-Operative Vision } \\
\hline
\end{tabular}

\section{DISCUSSION}

PXE is generally found in old age, the same age group are generally posted for cataract surgery. It is always essential to examine all eyes meticulously before surgery both before dilatation and after dilatation, because PXE can be missed if pupils are not dilated. In certain situations where large number of surgeries are to be performed and if pupils are dilated only just before surgery then the surgeon may face unexpected difficulty per-operatively.

Maximum incidence of PXE in our study was found in 6070 years age group which corresponds to other studies which also have shown increased prevalence after 60 years of age.[11,12] 
In our study a slight male preponderance was noticed. Studies about sex predilection in PXE are conflicting. Some studies reported male preponderance whereas Arvind et al. showed no sex predilection.[5] Some other studies have shown female preponerence.[13]

In our study the commonest problem encountered was poorly dilating pupil and was seen in $47.58 \%$ patients. Alfaiate et al.[12] found prevalence of $48.4 \%$. The commonest measure adopted by us was sphincterotomy. We also used iris hooks and pupillary stretching. We used dispersivecohesive viscoelastic soft-shell technique[14] which aided the pupillary dilatation and helped in maintaining it. Other workers have also used it for the same purpose.[15]

Careful capsulorrhexis is required because ant capsule of lens may be fragile in PXE. Zonular weakness is a major problem during cataract surgery. One has to do proper capsulorrhexis, hydrodissection and nuclear rotation to avoid lens dislocation. Even there can be late dislocation of intraocular lens postoperatively.[16] We found subluxation of lens during surgery in two cases. One of these cases was managed with capsular tension ring and the other was implanted anterior chamber lens.

We had rupture of posterior capsule and vitreous loss in 6 cases (4.84\%) and one additional case of vitreous loss due to subluxation of lens. In literature vitreous loss has been reported in up to $11 \%$ cases. $[17,18]$

In 8 cases $(6.45 \%)$ some amount of lens matter was retained. It was mainly due to non-dilating pupil and vitreous loss. Two cases underwent post-operative anterior chamber wash and others were followed up without any further complication.

Two cases showed per-operative IOL decentration: one could be stabilized by dialling and in the other case the IOL was removed and AC IOL was implanted.

Three cases showed minimal post-operative IOL decentration which were compatible with satisfactory visual outcome. Literature mentions that decentration may be due to the entire capsular bag getting decentered. $[19,20]$

Dehiscence of zonules was observed per-operatively in 4 cases $(3.22 \%)$, they were noticed during nucleus rotation, during nucleus delivery and during cortical aspiration. Postoperative hyphema was seen in one case only.

Majority patients obtained good post-operative vision in our study.

Our study as well as all other studies which have been referred to in the above write-up have clearly demonstrated increased incidence of various complications in the presence of pseudoexfoliation. In view of this it is recommended that a proper evaluation of cataract patients should be done to avoid surprises. Examination with pupillary dilatation is mandatory. Once we know the presence of pseudoexfoliation then we should keep essential things ready such as: pupil expansion devices, Capsular support devices and cohesive as well as dispersive viscoelastics.

A careful post-operative followup is desirable. One should look for IOL decentration. There are increased chances of posterior capsular opacification for which poor pupillary dilatation and consequent retained lens matter may be one of the contributory factors.

\section{CONCLUSIONS}

When cataract presents with PXE, there is an increased risk of surgical complications, the main being rigid pupil. Recognition of PXE preoperatively with proper examination and its management during surgery with various techniques and devices is essential to give a good vision to the patient.

\section{REFERENCES}

[1] Lindberg JG. Clinical investigations on depigmentation of the pupillary border and translucency of the iris in cases of senile cataract and in normal eyes in elderly persons. Acta Ophthalmol Suppl 1989;190:1-96.

[2] Ritch R. Exfoliation syndrome. Curr Opin Ophthalmol 2001;12(2):124-30.

[3] Streeten BW, Li ZY, Wallace RN, et al. Pseudoexfoliative fibrillopathy in visceral organs of a patient with pseudoexfoliation syndrome. Arch Ophthalmol 1992;110(12):1757-62.

[4] Sekeroglu MA, Bozkurt B, Irkec M, et al. Systemic associations and prevalence of exfoliation syndrome in patients scheduled for cataract surgery. Eur J Ophthalmol 2008;18(4):551-5.

[5] Arvind H, Raju P, Paul PG, et al. Pseudoexfoliation in South India. Br J Ophthalmol 2003;87(11):1321-3.

[6] Thomas R, Nirmalan PK, Krishnaiah S. Pseudoexfoliation in southern India: The Andhra Pradesh Eye Disease Study. Invest Ophthalmol Vis Sci 2005;46(4):1170-6.

[7] Zenkel M, Pöschl E, von der Mark K, et al. Differential gene expression in pseudoexfoliation syndrome. Invest Ophthalmol Vis Sci 2005;46(10):3742-52.

[8] Shrum KR, Hattenhauer MG, Hodge D. Cardiovascular and cerebrovascular mortality associated with ocular pseudoexfoliation, Am J Ophthalmol 2000;129(1):836.

[9] Chung H, Arora S, Damji KF, et al. Association of pseudoexfoliation syndrome with cardiovascular and cerebrovascular disease: a systematic review and meta-analysis. Can J Ophthalmol 2018;53(4):365-72.

[10] Scorolli L, Scorolli L, Campos EC, et al. Pseudoexfoliation syndrome: a cohort study on intraoperative complications in cataract surgery. Ophthalmologica 1998;212(4):278-80.

[11] Jawad M, Nadeem AU, Khan AU, et al. Complications of cataract surgery in patients with pseudoexfoliation syndrome. J Ayub Med Coll Abbottabad 2009;21(2):33-6.

[12] Alfaiate M, Leite E, Mira J, et al. Prevalence and surgical complications of pseudoexfoliation syndrome in Portuguese patients with senile cataract. J Cataract Refract Surg 1996;22(7):972-6.

[13] Avramides S, Traianidis P, Sakkias G. Cataract surgery and lens implantation in eyes with exfoliation syndrome. J Cataract Refract Surg 1997;23(4):583-7.

[14] Arshinoff SA. Dispersive-cohesive viscoelastic soft shell technique. J Cataract Refract Surg 1999;25(2):167-73.

[15] Fontana L, Coassin M, Iovieno A, et al. Cataract surgery in patients with pseudoex-foliation syndrome: current updates. Clin Ophthalmol 2017;11:1377-83. 
[16] Jehan FS, Mamalis N, Crandall AS. Spontaneous late dislocation of intraocular lens within the capsular bag in pseudoexfoliation patients. Ophthalmology 2001;108(10):1727-31.

[17] Shingleton BJ, Crandall AS, Ahmed II. Pseudoexfoliation and the cataract surgeon: preoperative, intraoperative and postoperative issues related to intraocular pressure, cataract, and intraocular lenses. J Cataract Refract Surg 2009;35(6):1101-20.
[18] Shastri L, Vasavada A. Phacoemulsification in Indian eyes with pseudoexfoliation syndrome. J Cataract Refract Surg 2001;27(10):1629-37.

[19] Shingleton BJ, Marvin AC, Heier JS, et al. Pseudoexfoliation: high risk factors for zonule weakness and concurrent vitrectomy during phacoemulsification. J Cataract Refract Surg 2010;36(8):1261-9.

[20] Ritch R, Schlötzer-Schrehardt U. Exfoliation syndrome. Surv Ophthalmol 2001;45(4):265-315. 